University of Nebraska - Lincoln

DigitalCommons@University of Nebraska - Lincoln

Faculty Publications in the Biological Sciences

Papers in the Biological Sciences

2021

\title{
The interspecific growth-mortality trade-off is not a general framework for tropical forest community structure
}

\author{
Sabrina E. Russo \\ University of Nebraska-Lincoln, srusso2@unl.edu \\ Sean M. McMahon \\ Smithsonian Institute, Washington DC, mcmahons@si.edu \\ Matteo Detto \\ Smithsonian Institute, Washington DC, mdetto@princeton.edu \\ Glenn Ledder \\ University of Nebraska - Lincoln, gledder1@unl.edu \\ S. Joseph Wright \\ Smithsonian Institute, Washington DC, wrightj@si.edu \\ Follow this and additional works at: https://digitalcommons.unl.edu/bioscifacpub \\ See next page for additional authors \\ Part of the Biology Commons, and the Forest Biology Commons
}

Russo, Sabrina E.; McMahon, Sean M.; Detto, Matteo; Ledder, Glenn; Wright, S. Joseph; Condit, Richard S.; Davies, Stuart J.; Ashton, Peter S.; Bunyavejchewin, Sarayudh; Chang-Yang, Chia-Hao; Ediriweera, Sisira; Ewango, Corneille E.N.; Fletcher, Christine; Foster, Robin B.; Gunatilleke, C.V. Savi; Gunatilleke, I.A.U. Nimal; Hart, Terese; Hseih, Chang-Fu; Hubbell, Stephen P.; Itoh, Akira; Kassim, Abdul Rahman; Leong, Yao Tze; Lin, Yi Ching; Makana, Jean-Remy; Mohamad, Mohizah Bt.; Ong, Perry; Sugiyama, Anna; Sun, I-Fang; Tan, Sylvester; Thompson, Jill; Yamakura, Takuo; Yap, Sandra L.; and Zimmerman, Jess K., "The interspecific growth-mortality trade-off is not a general framework for tropical forest community structure" (2021). Faculty Publications in the Biological Sciences. 858.

https://digitalcommons.unl.edu/bioscifacpub/858

This Article is brought to you for free and open access by the Papers in the Biological Sciences at DigitalCommons@University of Nebraska - Lincoln. It has been accepted for inclusion in Faculty Publications in the Biological Sciences by an authorized administrator of DigitalCommons@University of Nebraska - Lincoln. 


\section{Authors}

Sabrina E. Russo, Sean M. McMahon, Matteo Detto, Glenn Ledder, S. Joseph Wright, Richard S. Condit, Stuart J. Davies, Peter S. Ashton, Sarayudh Bunyavejchewin, Chia-Hao Chang-Yang, Sisira Ediriweera, Corneille E.N. Ewango, Christine Fletcher, Robin B. Foster, C.V. Savi Gunatilleke, I.A.U. Nimal Gunatilleke, Terese Hart, Chang-Fu Hseih, Stephen P. Hubbell, Akira Itoh, Abdul Rahman Kassim, Yao Tze Leong, Yi Ching Lin, Jean-Remy Makana, Mohizah Bt. Mohamad, Perry Ong, Anna Sugiyama, I-Fang Sun, Sylvester Tan, Jill Thompson, Takuo Yamakura, Sandra L. Yap, and Jess K. Zimmerman 


\section{The interspecific growth-mortality trade-off is not a general framework for tropical forest community structure}

Sabrina E. Russo, ${ }^{1}$ Sean M. McMahon, ${ }^{2,3}$ Matteo Detto, ${ }^{2,4}$

Glenn Ledder, ${ }^{5}$ S. Joseph Wright, ${ }^{2}$ Richard S. Condit, ${ }^{6}$

Stuart J. Davies, ${ }^{2}$ Peter S. Ashton, ${ }^{7}$

Sarayudh Bunyavejchewin, ${ }^{8}$ Chia-Hao Chang-Yang, ${ }^{9}$

Sisira Ediriweera, ${ }^{10}$ Corneille E. N. Ewango, ${ }^{11}$

Christine Fletcher, ${ }^{12}$ Robin B. Foster, ${ }^{13}$

C. V. Savi Gunatilleke, ${ }^{14}$ I. A. U. Nimal Gunatilleke, ${ }^{14}$

Terese Hart, ${ }^{15}$ Chang-Fu Hsieh, ${ }^{16}$ Stephen P. Hubbell, ${ }^{17}$

Akira Itoh, ${ }^{18}$ Abdul Rahman Kassim, ${ }^{12,} 29$ Yao Tze Leong, ${ }^{12}$ Yi

Ching Lin, ${ }^{19}$ Jean-Remy Makana, ${ }^{20}$

Mohizah Bt. Mohamad, ${ }^{21}$ Perry Ong, ${ }^{22,} 30$ Anna Sugiyama, ${ }^{23}$

I-Fang Sun, ${ }^{24}$ Sylvester Tan, ${ }^{25}$ Jill Thompson, ${ }^{26,27}$

Takuo Yamakura, ${ }^{18}$ Sandra L. Yap, ${ }^{28}$ and

Jess K. Zimmerman ${ }^{27}$

Published in Nature Ecology \& Evolution 5 (February 2021), pp 174-183.

doi:10.1038/s41559-020-01340-9

Copyright (c) 2020 Sabrina E. Russo et al. Published by Springer Nature Limited. Used by permission.

Submitted 3 July 2019; accepted 5 October 2020; published 16 November 2020.

Citation: Russo, S.E., McMahon, S.M., Detto, M. et al. The interspecific growth-mortality trade-off is not a general framework for tropical forest community structure. Nat Ecol Evol 5, 174-183 (2021). https://doi.org/10.1038/s41559-020-01340-9 
1 School of Biological Science and Center for Plant Science Innovation, University of Nebraska, Lincoln, NE, USA.

2 Center for Tropical Forest Science-Forest Global Earth Observatory, Smithsonian Institute, Washington DC, USA.

3 Forest Ecology Group, Smithsonian Environmental Research Center, Edgewater, MD, USA.

4 Department of Ecology and Evolutionary Biology, Princeton University, Princeton, NJ, USA.

5 Department of Mathematics, University of Nebraska, Lincoln, NE, USA.

6 Morton Arboretum, Lisle, IL, USA.

7 Department of Organismic and Evolutionary Biology, Harvard University, Cambridge, MA, USA.

8 Research Office, Department of National Parks, Wildlife and Plant Conservation, Bangkok, Thailand.

9 Department of Biological Sciences, National Sun Yat-sen University, Kaohsiung City, Taiwan.

10 Department of Science and Technology, Uva Wellassa University, Badulla, Sri Lanka.

11 Faculty of Renewable Natural Resources Management \& Faculty of Sciences, University of Kisangani, Kinshasa, Democratic Republic of Congo.

12 Forest Research Institute Malaysia, Selangor, Malaysia.

13 Botany Department, The Field Museum, Chicago, IL, USA.

14 Faculty of Science, Department of Botany, University of Peradeniya, Peradeniya, Sri Lanka.

15 Tshuapa-Lomami-Lualaba Project, Lukuru Wildlife Research Foundation, Kinshasa, Democratic Republic of the Congo.

16 Institute of Ecology and Evolutionary Biology, National Taiwan University, Taipei, Taiwan.

17 Department of Ecology and Evolutionary Biology, University of California, Los Angeles, Los Angeles, CA, USA.

18 Graduate School of Science, Osaka City University, Osaka, Japan.

19 Department of Life Science, Tunghai University, Taichung, Taiwan.

20 Faculty of Sciences, University of Kisangani, Kinshasa, Democratic Republic of Congo.

21 Forest Department Sarawak, Bangunan Wisma Sumber Alam, Kuching, Malaysia.

22 Institute of Biology, University of the Philippines Diliman, Quezon City, Philippines.

23 School of Life Sciences, Lyon Arboretum, University of Hawai'i at Mānoa, Honolulu, HI, USA.

24 Department of Natural Resources and Environmental Studies, National Dong Hwa University, Hualian, Taiwan.

25 Smithsonian ForestGEO, Lambir Hills National Park, Miri, Malaysia.

26 Centre for Ecology \& Hydrology, Bush Estate, Penicuik, UK.

27 Department of Environmental Sciences, University of Puerto Rico, Río Piedras, PR, USA.

28 Far Eastern University, Manila, Philippines.

29 Deceased: Abdul Rahman Kassim.

30 Deceased: Perry Ong.

Correspondence and requests for materials — S. E. Russo, email: srusso2@unl.edu

\section{Abstract}

Resource allocation within trees is a zero-sum game. Unavoidable trade-offs dictate that allocation to growth-promoting functions curtails other functions, generating a gradient of investment in growth versus survival along which tree species align, known as the 
interspecific growth-mortality trade-off. This paradigm is widely accepted but not well established. Using demographic data for 1,111 tree species across ten tropical forests, we tested the generality of the growth-mortality trade-off and evaluated its underlying drivers using two species-specific parameters describing resource allocation strategies: tolerance of resource limitation and responsiveness of allocation to resource access. Globally, a canonical growth-mortality trade-off emerged, but the trade-off was strongly observed only in less disturbance-prone forests, which contained diverse resource allocation strategies. Only half of disturbance-prone forests, which lacked tolerant species, exhibited the trade-off. Supported by a theoretical model, our findings raise questions about whether the growth-mortality trade-off is a universally applicable organizing framework for understanding tropical forest community structure.

A widely accepted pattern of life-history trade-offs in forests is the interspecific growth-mortality trade-off. This trade-off emerges because tree species are arrayed on a continuum of resource allocation strategies, from species that grow slowly and survive well to species that grow more quickly, but at the cost of higher mortality. ${ }^{1-8}$ Provided that species in a forest community fall along such an axis, the growth-mortality trade-off may equalize species' relative fitness and thereby contribute to diversity maintenance. ${ }^{9-11}$ The generality of the growth-mortality trade-off, however, has not been unequivocally established because of the need for large demographic datasets spanning multiple census intervals, diverse tree species and different forest types. Moreover, the exploration of the underlying drivers related to alternative resource allocation strategies has focused on functional traits, which often have poor predictive power and have not always shown the expected relationships. 6,12,13

Here, we define alternative resource allocation strategies on the basis of the within-species mortality-growth relationship, which reflects demographically integrated outcomes of allocation in response to variation in resource availability. In the interspecific growth-mortality trade-off, species that grow quickly tend to have higher mortality rates (Fig. 1a), 3,14,15 but within species, mortality is usually higher for individuals that grow slowly (Fig. 1b).3,16,17 The lower mortality of faster-growing individuals implies that these trees have greater access to above- and/or below-ground resources, allowing more resources to be allocated towards reducing the risk of death. Tolerance of resource limitation has long been viewed as an important dimension of plant ecological strategies. ${ }^{18,19}$ The mortality rate when growth falls to zero (the within species mortality-growth intercept; 
a

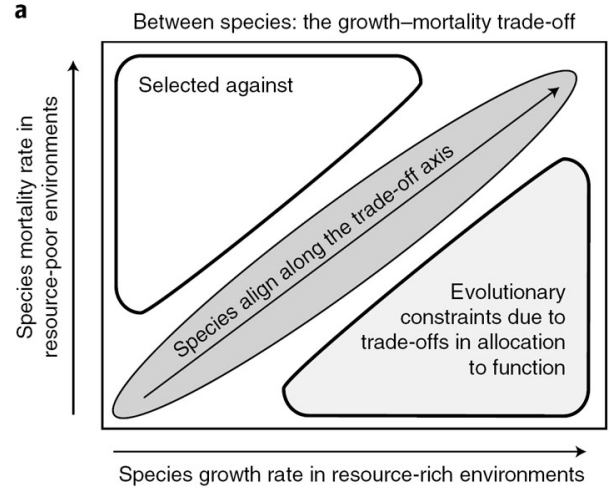

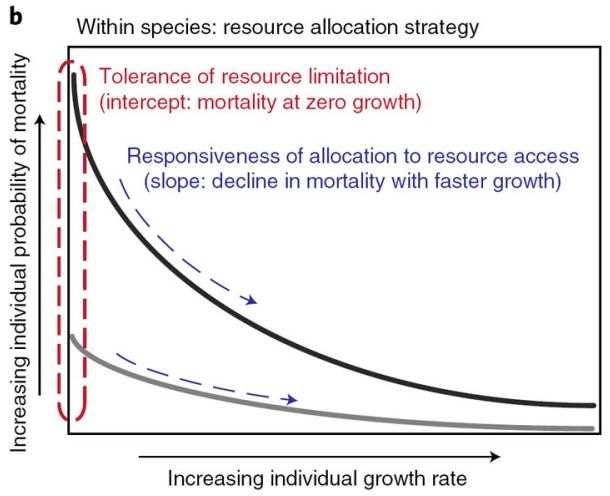

Fig. 1. Conceptual model of the between- and within-species relationships between mortality and growth for trees. a) Species fall along the interspecific growth-mortality trade-off axis, which represents a trade-off between the ability to grow quickly when resources are plentiful and the ability to survive when resources are scarce. While responses to light have been emphasized in defining the trade-off, 3,6 belowground resources also affect tree growth and mortality, ${ }^{5,22}$ and so we consider resources in more general terms. The trade-off arises because tree species with slow growth and high mortality (upper left corner) are selected against, because this combination of vital rates would not be successful in competition with species that grow faster and/or have lower mortality. While a fast growth-low mortality strategy (bottom right corner) would be successful, physiological and allocationbased constraints impose limits, since allocation to functions that favor fast growth reduce allocation to functions that favor survival. ${ }^{56,57}$ How trees resolve such tradeoffs in resource allocation is thought to generate the interspecific trade-off. b) In contrast to the between-species relationship, within species, individual mortality probability declines with individual growth rate. The shape of the within-species mortality-growth relationship reflects both evolutionary and ecological influences and integrates differences among individuals in access to exogenous resources and strategies of allocation of endogenous resources. We use the empirical withinspecies mortality-growth relationship for a tree species to derive proxies for two species-specific dimensions of resource allocation strategy thought to underlie the interspecific growth-mortality trade-off: tolerance of resource limitation and responsiveness of allocation to resource access, where 'access' integrates both the availability of resources in the environment and a tree's ability to acquire those resources. We mechanistically model tolerance and responsiveness in a theoretical model (Supplementary Appendix 2); however, these dimensions of allocation strategy are not directly observable in the empirical data, and so here we use proxy parameters derived from the within-species mortality-growth relationship. The intercept is the mortality rate when growth falls to zero, which reflects tolerance in that it quantifies how well a tree can survive in environmental conditions that curtail growth, which are generally conditions of resource limitation. The slope quantifies how quickly increases in growth translate into reductions in mortality, which reflects how access to resources directly affects mortality and, importantly, how it affects mortality as mediated by changes in allocation to functions affecting growth versus survival. 
Fig. 1b) provides an estimate of tolerance and reflects how well a tree can survive with limited ability to acquire resources and allocate them to reducing mortality. The slope of the within-species mortality-growth relationship (Fig. 1b) quantifies how quickly increases in growth translate into reductions in mortality, which we define as the responsiveness of species' allocation to resource access. Access to resources is a function of both the resource availability in the environment and a tree's ability to acquire those resources. Individual trees with ample access to resources generally grow faster, which can further increase their access to resources ${ }^{20}$ and thereby reduce the impact of allocation trade-offs on demographic rates. ${ }^{21}$ The slope therefore reflects variation in access to resources, as well as how trees resolve trade-offs in allocation to growth versus other functions, including survival and reproduction.

The shape of the within-species mortality-growth relationship varies widely among tree species, $, 3,14,15$ reflecting diversity in tolerance and responsiveness. Forests differ in their long-term environments (for example, climate, resource availability and disturbance history), so they should also differ in how the underlying trade-offs related to resource access and allocation affect the favorability of different tolerance-responsiveness strategies. Here, we use data on tree growth and mortality for 1,111 tree species from ten tropical forests representing disparate biogeographic regions and with varying geology, climate and disturbance regimes (Supplementary Table 1) to test the pantropical generality of the interspecific growth- mortality tradeoff and the allocation strategies hypothesized to underpin it. The ten tropical forests sample the African (Ituri) and Asian (Fushan, Huai Kha Khaeng (HKK), Khao Chong, Lambir, Palanan, Pasoh and Sinharaja) tropics, as well as the neotropics (Barro Colorado Island $(\mathrm{BCl})$ and Luquillo) (Supplementary Table 1). To evaluate our empirical findings, we developed a theoretical demographic allocation model accounting for resource availability in the environment to explore the types of allocation strategies yielding the shapes of the within-species mortality-growth relationships seen in the real forests we studied and to identify the scenarios under which the interspecific growth-mortality trade-off arises. 


\section{Results}

Generality of the interspecific growth-mortality trade-off. Tree species varied substantially in the shapes of the within-species relationship between individual mortality and prior growth rate (Fig. 2 and Supplementary Fig. 1), which generally explained mortality better than equivalent models without growth as a predictor (Supplementary Table 2). From these models, tolerance and responsiveness parameters were estimated for each species (Fig. 1b), and the tolerance parameter and 95th quantile of the growth rate were used to define the interspecific growth-mortality trade-off. At the global scale, the trade-off was observed ( $r=0.44, P<0.001$ ) across the 1,097 species encompassed by the first three-census interval for each forest (Fig. 3 ). We found evidence for the growth-mortality trade-off in eight of the ten tropical forests examined, but the trade-off varied considerably in strength among these forests (Table 1). Statistically significant correlation coefficients ranged from 0.24 (Pasoh) to 0.56 (Lambir) and were largely consistent within each forest among different census intervals, suggesting that the trade-off emerges from the features of the forest. Six of the eight forests that exhibited the growth-mortality trade-off (BCl, Ituri, Khao Chong, Lambir, Pasoh and Sinharaja) are less disturbance-prone. The least dynamic of these (Lambir, Pasoh and

Fig. 2. Within-species relationships between individual mortality and prior growth for six exemplar tropical tree species. a) Cecropia insignis (Urticaceae), a pioneer tree species from $\mathrm{BCl}$ (intolerant-responsive). b) Cecropia schreberiana (Urticaceae), a pioneer tree species from Luquillo (intolerant-responsive). c) Dryobalanops lanceolata (Dipterocarpaceae), an emergent tree species specializing on more fertile soil from Lambir (intolerant-responsive). d) Dryobalanops aromatica (Dipterocarpaceae), an emergent tree species specializing on less fertile soil from Lambir (intolerant-responsive). e) Anisophyllea corneri (Anisophylleaceae), a shade-tolerant subcanopy tree species at Pasoh (tolerant-unresponsive). f) Dillenia retusa (Dilleniaceae), a shade-tolerant canopy tree species at Sinharaja (tolerant-unresponsive). The red lines show the mortality-growth curves predicted from the model fit, and the blue shaded regions show the $95 \%$ confidence bands, at the species' mean diameter at breast height $(\mathrm{DBH})$. The black circles show the predicted mortality probability for each tree at its observed growth rate and $\mathrm{DBH}$, and the symbol size is scaled to $\mathrm{DBH}$. Individuals deviate from the predicted line because their DBHs differ from the mean. The rug plots at the bottom and top of each graph show trees surviving (below) and dying (above) at their observed growth rate. Note the changes in the $x$-axis scales. 

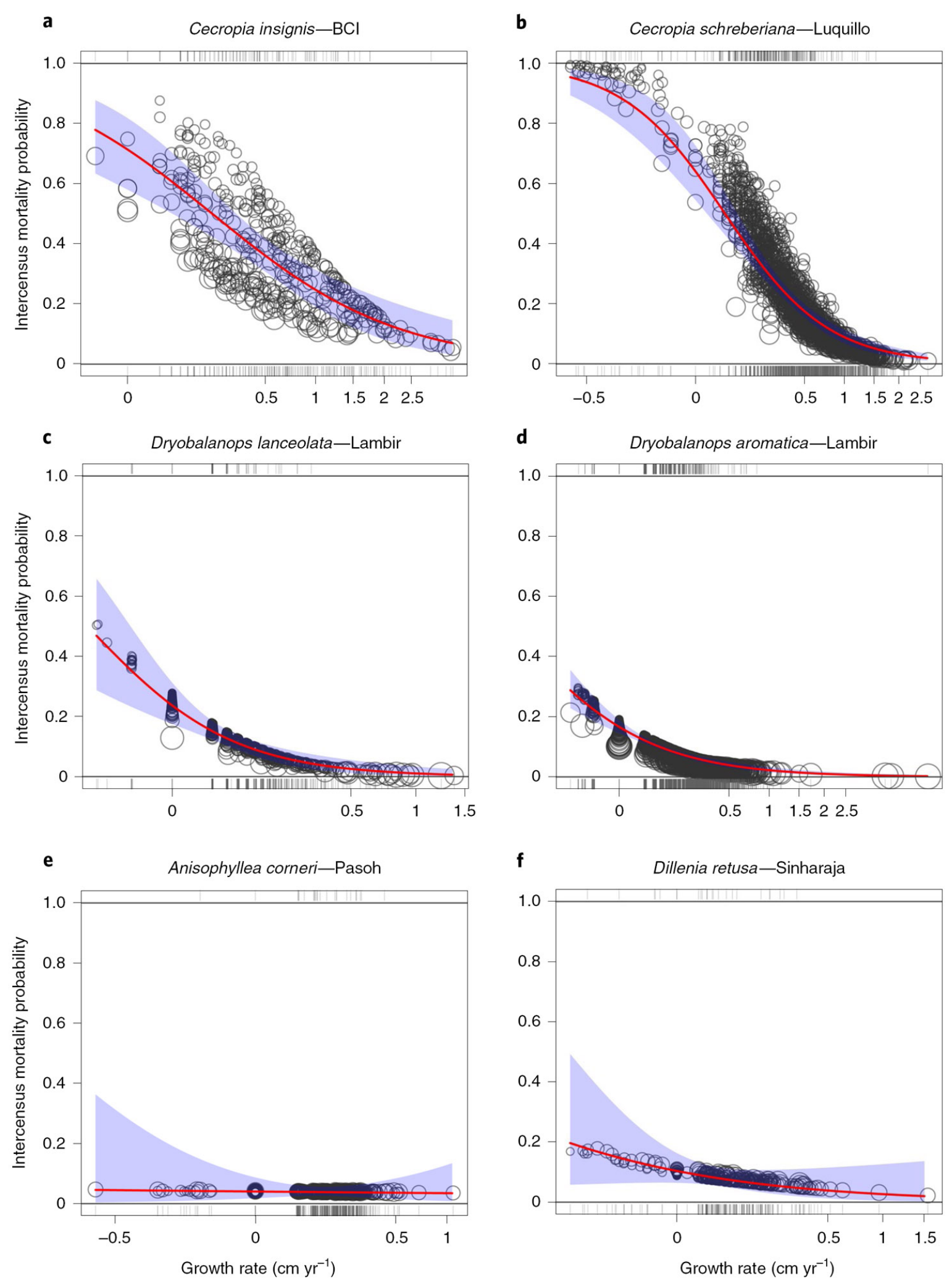


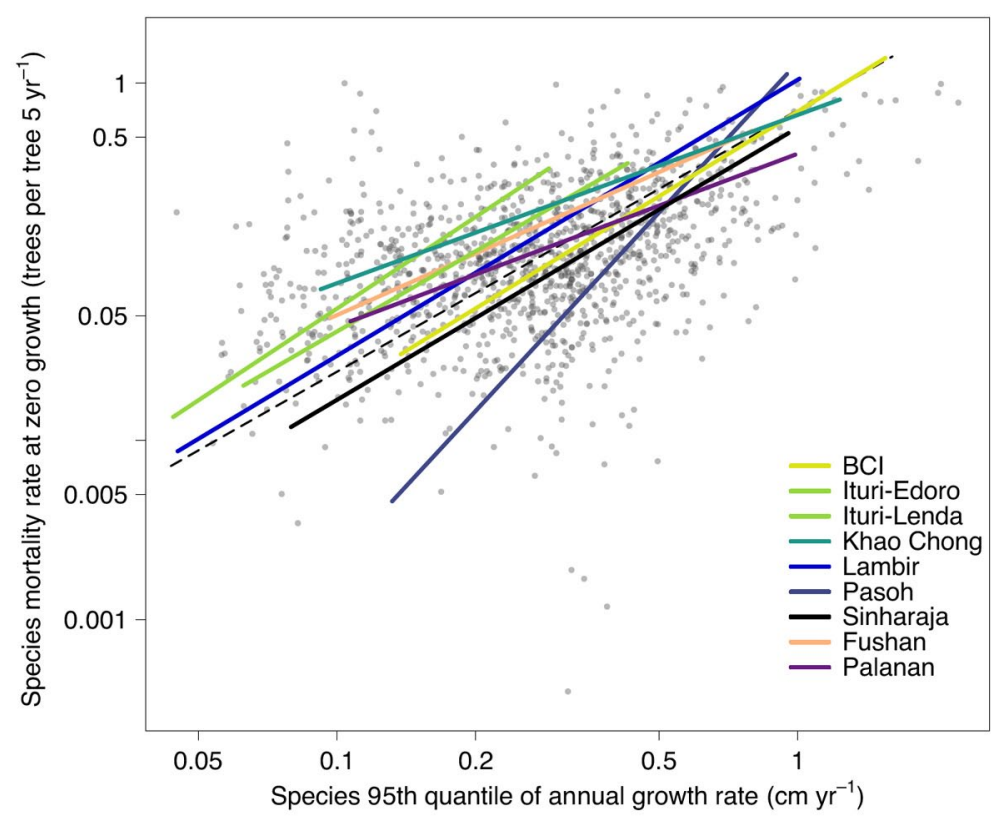

Fig. 3. The interspecific growth-mortality trade-off for 1,097 woody tree species in ten forests. Each point represents the estimated mortality rate at zero growth rate (the tolerance parameter) and the 95th quantile of the growth rate for a species, with the first three-census interval represented for each forest, so that each species appears only once per forest. The dashed black line is the major axis regression line across all species and represents the growth-mortality trade-off at the global scale for the tropical tree species in our study. The solid colored lines represent the major axis regression lines for forests with a statistically significant correlation (Table 1), colored according to the legend. Note that Ituri-Edoro and Ituri-Lenda consist of a total of four distinct forest plots, a pair of plots separated by $500 \mathrm{~m}$ at each site, Edoro and Lenda, which are within $30 \mathrm{~km}$ of each other. ${ }^{58}$ We joined the data from the two plots at each site for analyses, and thus report results for each site separately, but we discuss overall patterns for both sites together (referred to as Ituri), as the patterns were generally similar.

Sinharaja) have some of the mildest disturbance regimes, consisting mainly of small-scale gap dynamics, less seasonal climates and often very dark understories, and they occur on fairly nutrient-depleted soils. In contrast, BCl, Ituri and Khao Chong are moderately dynamic, having more seasonal climates with more intense dry seasons and more open canopies, or occurring on more fertile soils. Both forests that did not exhibit the trade-off (HKK and Luquillo) and one of the forests with a weaker correlation (Palanan) are highly dynamic and are regularly disturbed by typhoons, hurricanes or fire (Table 1 and Supplementary Table 1). 
Table 1. Strength of the interspecific growth-mortality trade-off, as measured by the correlations of species' estimated mortality rates at zero growth rate (that is, the tolerance parameter) with the 95th quantile of the growth rate for woody tree species in ten tropical forest dynamics plots

\begin{tabular}{lrrr} 
Plot, census year & Number of species & $r$ & $P$ \\
\hline Less disturbance-prone & & & \\
BCl, 1985 & 101 & 0.48 & $<0.001$ \\
BCI, 1990 & 98 & 0.46 & $<0.001$ \\
BCI, 1995 & 91 & 0.46 & $<0.001$ \\
BCl, 2000 & 90 & 0.43 & $<0.001$ \\
Ituri-Edoro, 1994 & 54 & 0.33 & 0.014 \\
Ituri-Lenda, 1994 & 47 & 0.41 & 0.004 \\
Khao Chong, 2000 & 104 & 0.41 & $<0.001$ \\
Lambir, 1992 & 359 & 0.56 & $<0.001$ \\
Lambir, 1997 & 352 & 0.54 & $<0.001$ \\
Pasoh, 1986 & 312 & 0.34 & $<0.001$ \\
Pasoh, 1990 & 295 & 0.33 & $<0.001$ \\
Pasoh, 1995 & 296 & 0.29 & $<0.001$ \\
Pasoh, 2000 & 0.24 & $<0.001$ \\
Sinharaja, 1993 & 281 & 0.31 & 0.004 \\
More disturbance-prone & 85 & & \\
Fushan, 2004 & & 0.38 & 0.016 \\
HKK, 1992 & 39 & 0.19 & 0.255 \\
HKK, 1999 & 39 & 0.25 & 0.105 \\
Luquillo, 1990 & 0.08 & 0.678 \\
Luquillo, 1995 & 42 & 0.12 & 0.557 \\
Luquillo, 2000 & 0.27 & 0.176 \\
Palanan, 1998 & 31 & 0.26 & 0.045 \\
\hline
\end{tabular}

The Pearson correlation coefficient $(r)$ and probability $(P)$ for 21 forest plot $\times$ census-year combinations are shown, along with the number of tree species included in each analysis. The forest plots are grouped according to disturbance severity, with disturbance associated with fire at HKK and with typhoons and hurricanes at Fushan, Luquillo and Palanan. The initial census year used to calculate growth and mortality for successive censuses is listed along with the plot name (Supplementary Table 1). Correlation statistics in bold are statistically significant at $\alpha<0.05$. Since the same species can occur in multiple censuses in a plot or in multiple plots, the sum of the numbers of species in this table is greater than the total number of unique species analyzed.

Variation among forests in resource allocation strategies. Ordinated on the basis of species' resource allocation strategies (that is, their tolerance and responsiveness parameter values), forests occupied different regions of the global strategy space (Fig. 4a), and how they grouped with respect to biogeography, geology, climate seasonality and disturbance was inconsistent. Forests in different biogeographic regions often grouped together: Luquillo (Puerto Rico) grouped with HKK (Thailand), Khao Chong (Thailand) grouped with $\mathrm{BCl}$ (Panama), and Ituri-Edoro, 
Ituri-Lenda (Democratic Republic of Congo), Lambir (Malaysia) and Sinharaja (Sri Lanka) grouped together. The first pair are disturbance-prone; the second have more seasonal rainfall regimes and experience occasional, moderate-intensity disturbances; and the last group represents forests growing on more nutrient-depleted soils with lower-intensity, smaller-scale disturbances and ample, year-round rainfall (Supplementary Table 1). While the variation in disturbance regimes was clearly influential in defining differences among forests in strategy space, not all disturbance-prone forests clustered together. Fushan and Palanan (cyclonic forests) did not cluster with each other or with the other two disturbance-prone forests (HKK and Luquillo), which themselves clustered together, despite having dramatically different annual rainfall (Supplementary Table 1), further illustrating that climate regime was not always associated with forest grouping patterns. Although Lambir and Sinharaja grouped together and have high, year-round precipitation, other forests (Pasoh and Palanan) with similar climate regimes did not group with them, while Ituri-Edoro and Ituri-Lenda, with a three-month dry season, did group with them. Fushan occupied a more isolated region of strategy space, while $\mathrm{BCl}$ and Khao Chong, with similar annual rainfall, grouped together. Further plot-specific results describing the importance of legacies of disturbance and soil fertility for determining the distributions of tolerance-responsiveness strategies are presented in Supplementary Appendix 1.

Fig. 4. Variation among forests in tree species' tolerance and responsiveness strategies. a) Principal component (PC) analysis of variation in the parameters of the within-species relationship between mortality and prior growth for ten tropical forests. The ellipses represent $95 \%$ confidence intervals, calculated on the basis of the standard error, around the centroid for each forest. The different colors indicate the different forests, as shown in the legend in the figure, with less disturbanceprone forests shown in yellow, green and blue ellipses and circular symbols, and more disturbance-prone forests shown in pink, red and brown ellipses and triangular symbols. Since there are only two parameters-the intercept (species' tolerance of resource limitation) and slope (responsiveness to resources) - the two principal components together account for $100 \%$ of their variation. So that species appear only once, only the first three censuses in a plot were used in this figure, comprising 1,097 species across all plots. b) Representation of the four tolerance and responsiveness mortality-growth strategies in more disturbance-prone (Fushan, HKK, Luquillo and Palanan) versus less disturbance-prone (BCl, Ituri-Edoro, Ituri-Lenda, Khao Chong, Lambir, Pasoh and Sinharaja) forests for the first census interval for each forest. See Supplementary Table 3 for the forest-specific values across different censuses. 


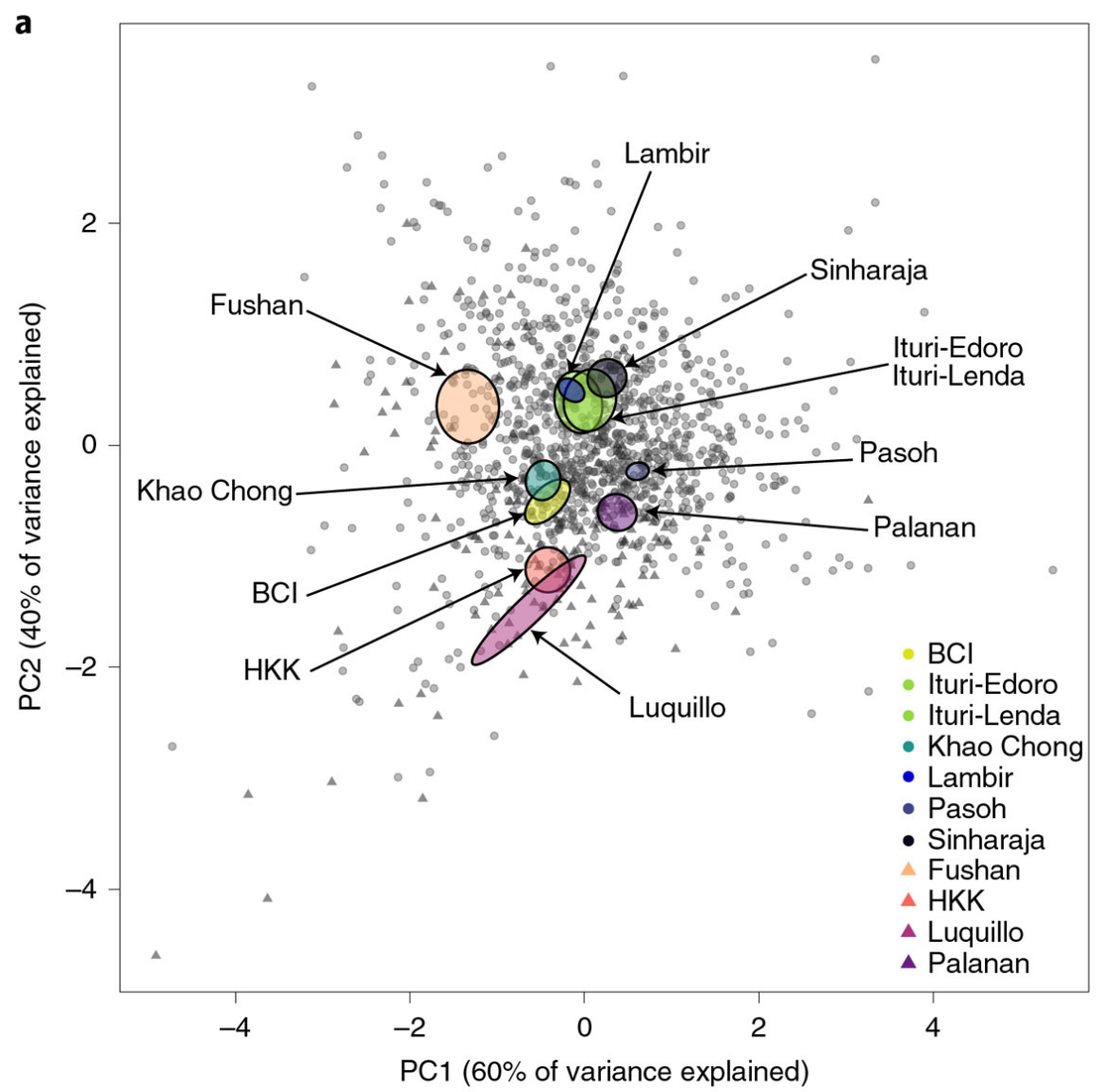

b

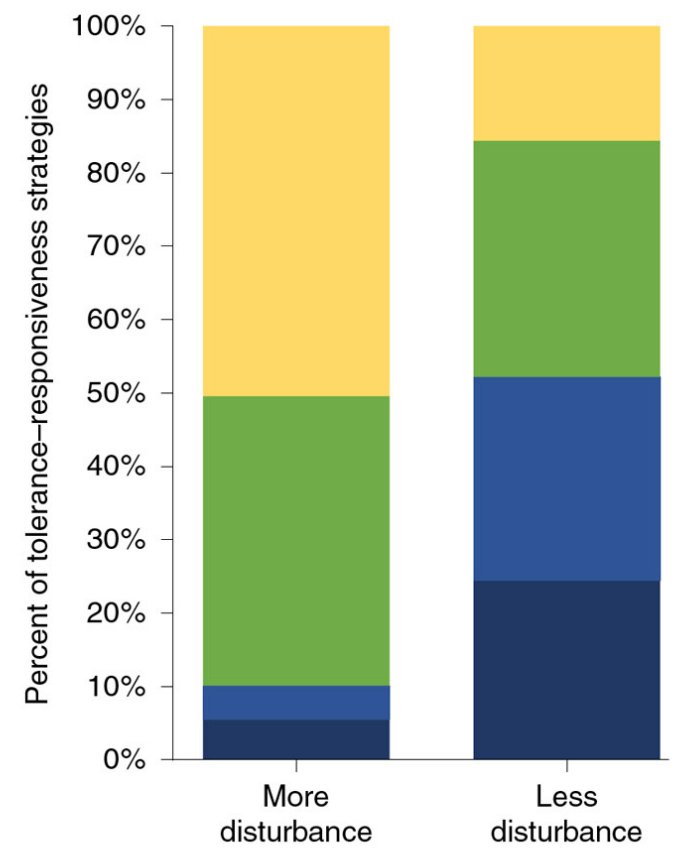

- Intolerant-unresponsive

- Intolerant-responsive

- Tolerant-unresponsive

- Tolerant-responsive

Level of disturbance 
We divided the resource allocation strategy space into four categories on the basis of the medians of the tolerance and responsiveness parameters across all species and plots: tolerant-unresponsive, tolerant- responsive, intolerant-unresponsive and intolerant-responsive. We then categorized the species in each forest according to their parameter values (Supplementary Figs. 2 and 3). These groups do not represent absolute categories but rather provide an informative way to make relative comparisons of how the frequency of species with different tolerance-responsiveness strategies varies among the forests in our analysis. Six species are shown in Fig. 2 as examples illustrating variation in these strategies. Light-demanding species (Fig. $2 \mathrm{a}, \mathrm{b})$ were generally intolerant-responsive (Cecropia insignis at $\mathrm{BCl}$ and C. schreberiana at Luquillo; Fig. 2a,b). Shade-tolerant species (Fig. 2c-f) generally had lower intercepts than light-demanding species, but there was considerable variation in both classes, probably driven by other physiological response traits. For example, two congeneric shade-tolerant emergent tree species from Lambir that specialize on more fertile clay (Dryobalanops lanceolata; Fig. 2c) or infertile sandy loam (D. aromatica; Fig. 2d) were both classified as intolerant-responsive. However, D. lanceolata had a higher intercept and steeper slope, consistent with the faster growth and higher mortality typical of species specializing on the more fertile clay at Lambir. ${ }^{22}$ An extremely shade-tolerant tree species, Anisophyllea corneri, showed the expected tolerant-unresponsive strategy in Pasoh, as did Dillenia retusa at Sinharaja (Fig. 2e,f).

On the basis of the data from the first three censuses for all plots, forests were significantly associated with particular tolerance and responsiveness strategies $\left(\chi^{2}=612.2\right.$, d.f. $=30, P<0.001$; Supplementary Table 3). Seven of the eight forests in which the growth-mortality trade-off was found ( $\mathrm{BCl}$, Ituri, Khao Chong, Lambir, Palanan, Pasoh and Sinharaja) had a more even representation of species among the four types of strategies, whereas forests in which the trade-off was not found (HKK and Luquillo) had a more uneven representation of strategies, as they lacked or had very few species in at least two tolerance-responsiveness categories (Supplementary Table 3). This dichotomy generally corresponded to the rate of stem turnover in the forest (forest dynamism), with the exception of Fushan, which exhibited the trade-off but was dominated by intolerant-responsive 
species. Tolerant strategies were notably under-represented in the more disturbance-prone forests (Fig. 4b). Intolerant species represented $>80 \%$ of the species in Fushan and $>90 \%$ in HKK and Luquillo. Indeed, Luquillo, which experiences intense but infrequent hurricanes, had only five species categorized as tolerant, and HKK, with a strong annual dry season and fire disturbances, had only one tolerant species (Supplementary Table 3). Thus, the range of tolerance-responsiveness strategies that are adaptive in disturbance-prone forests, of which 50\% did not exhibit the growth-mortality trade-off, was fundamentally different and much more restricted than in less disturbance-prone forests, which always exhibited the trade-off.

In the five forests for which the within-species mortality- growth relationships could be fit for the same species in multiple three-census intervals ( $\mathrm{BCl}, \mathrm{HKK}$, Lambir, Luquillo and Pasoh), the estimates for the tolerance parameter were reasonably consistent across intervals for a species (pairwise correlation coefficient: mean, 0.73; range, 0.50-0.92; Supplementary Table 4). In contrast, the estimates of the responsiveness parameter were less consistent (pairwise correlation coefficient: mean, 0.26; range, 0.04-0.52; Supplementary Table 4). Reproduction is not explicitly represented in our analyses and should trade off with allocation to support faster growth and reduced mortality risk..$^{23}$ This is consistent with the greater within-species temporal variation in the responsiveness parameter in that diverting resources to reproduction could affect the balance between allocation to growth and allocation to survival.

Theoretical demographic allocation model. We developed a theoretical demographic allocation model (Supplementary Appendix 2) to explore how alternative resource allocation strategies shape withinspecies mortality-growth relationships. In our model, tree species differ only in their resource allocation strategy, which is defined by two parameters, $\delta_{0 i}$ and $\delta_{s i^{\prime}}$ describing the proportion of total biomass invested in functions promoting survival as function of the availability of all types of resources (for example, above- and belowground resources) in an individual tree's environment $(\omega)$. The parameter $\delta_{0 i}$ describes the proportion of biomass invested in survival independent of the environment $(\omega=0)$, and $\delta_{s i}$ describes how that investment changes as the environment improves $(\omega \rightarrow 1)$. We examined the 
relationships between $\omega$, the probability of dying $(p)$ and diameter growth $(\mathrm{d} D / \mathrm{d} t)$ using five allocation strategies (the colors refer to the different strategies in Fig. 5a,b; see the figure legend for the parameter values): (1) acquisitive (no allocation to survival functions; blue), (2) conservative (constant allocation to survival; red), (3) prudent (decreasing allocation to survival with better environments; gold), (4) opportunistic (acquisitive, but with increasing allocation to survival with better environments; purple) and (5) overconservative (some allocation to survival that increases in better environments; green). Regardless of the allocation strategy, trees always grow faster in better environments. However, since biomass allocated to survival does not contribute to growth, the increase in growth depends on allocation, with strategies allocating less to survival growing faster in better environments (Supplementary Fig. 4).

The different allocation strategies produce variation in the relationship between mortality probability and the environment (Fig. 5a), which affects the shapes of the within-species relationships between mortality

Fig. 5. Analysis of a theoretical demographic allocation model showing the consequences of variation in resource allocation strategies for the growth- mortality trade-off. $\mathbf{a}, \mathbf{b})$ Five strategies of resource allocation to survival functions are modelled (see the in-figure legend), resulting in variation in the individual-level mortality probability with respect to the resource availability of the environment in a and with respect to the diameter growth rate in $\mathbf{b}$. $\mathbf{c}, \mathbf{d})$ The within-species mortality-growth relationships of 25 simulated species representing a wide range of different resource allocation strategies are modelled in c, and the corresponding interspecific growth-mortality trade-off for species with these strategies is presented in $\mathbf{d}$. The growth-mortality trade-off relationship in $\mathbf{d}$ is statistically significant (Pearson correlation; $r=0.72, P<0.001$ ). One species (that is, strategy) is represented by one line in $\mathbf{a}-\mathbf{c}$ and by one point in $\mathbf{d}$. Resource availability in the environment varies from the lowest $(\omega=0)$ to the highest $(\omega=1)$ availability, and each curve corresponds to one species-level resource allocation strategy defined by $\delta_{0 i}$ (the proportion of biomass allocated to survival functions in the poorest environment, $\omega=0$ ) and $\delta_{s i}$ (the rate of change of the proportion of biomass allocated to survival functions with respect to the environment (linear with $\omega$ )). Note that in $\mathbf{b}$ and $\mathbf{c}$, the curves for each species do not extend to all possible growth rates because species that allocate more biomass to survival functions will grow slower than species that allocate less. Thus, the maximum growth rate for each species, corresponding to the right end point of each curve, depends on the maximum amount of resources left over for growth in an ideal environment $(\omega=1)$. See Supplementary Appendix 2 for the detailed model description and analysis. 
probability and diameter growth rate (Fig. 5b), resembling the empirical relationships (Fig. 2). The correspondence between the empirical and theoretical results illustrates that interspecific variation in the shapes of the within-species mortality-growth relationship can arise solely due to varying strategies of allocation of resources to survival, in combination with varying resource availability in the environment. In Fig. 5, the acquisitive, conservative, opportunistic and overconservative strategies (blue, red, purple and green, respectively) correspond to most of the empirically observed shapes, whereas the prudent strategy (gold), while present, was rarer (Supplementary Fig. 1).
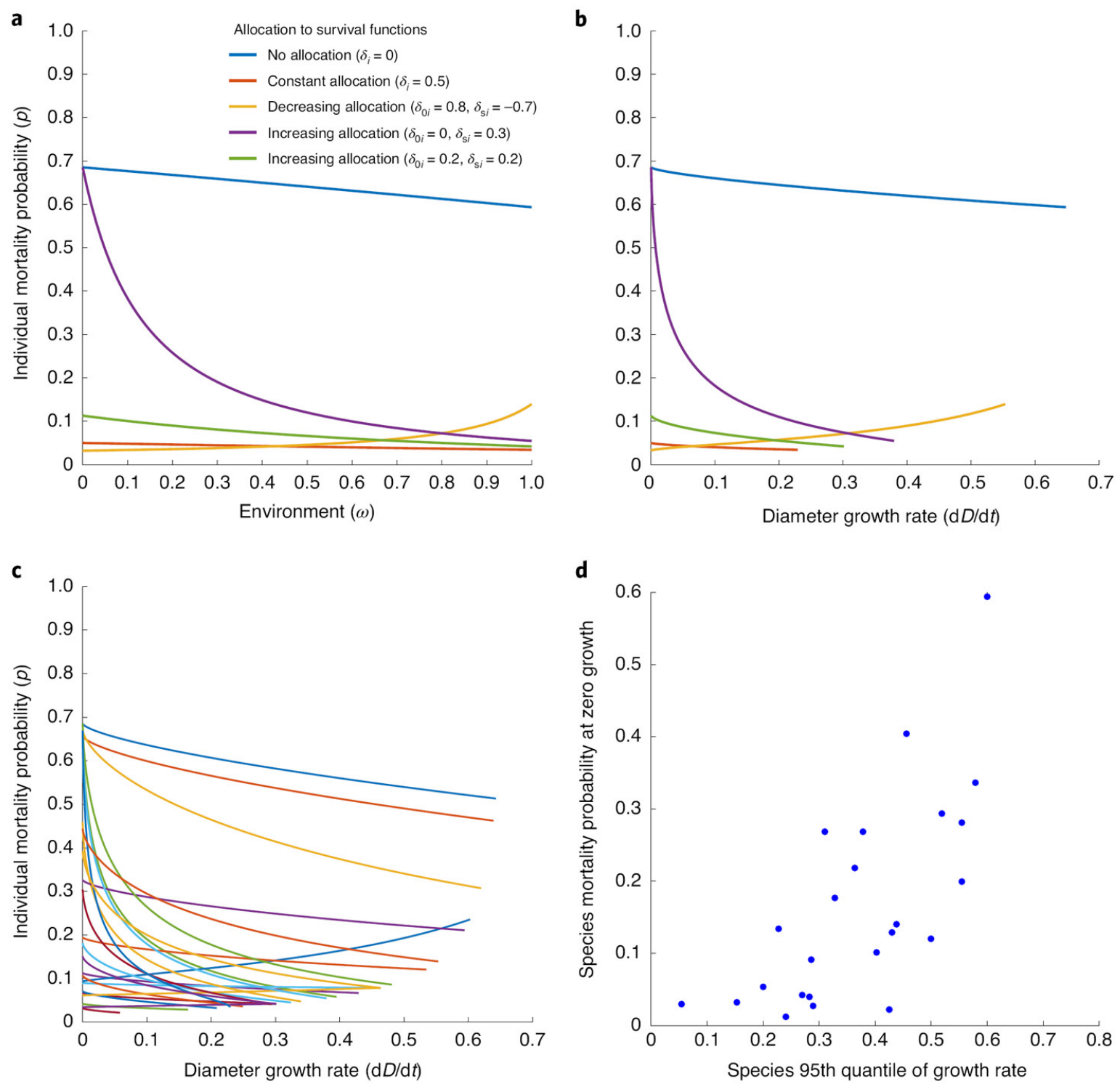
The acquisitive (analogous to intolerant-unresponsive) and opportunistic (analogous to intolerant-responsive) strategies represent different strategies for taking advantage of environmental resources. They both allocate no biomass to survival in the poorest environment, but as the environment improves, the acquisitive species allocates all of the additional resources to growth. When there is no direct survival benefit (that is, not mediated through allocation) of being in a better environment, then the mortality probability of the acquisitive strategy is always high and invariant with growth rate (unresponsive). In contrast, because the opportunistic strategy allocates more to survival in better environments, its mortality probability starts high but declines as its growth rate increases (responsive). The acquisitive strategy corresponds to the most extreme light-demanding pioneer species that are fast-growing and short-lived, whereas the opportunistic strategy corresponds to less light-demanding species. Like the acquisitive strategy, the conservative strategy displays no plasticity in allocation, but it allocates the same non-zero amount to survival in all environments (tolerant-unresponsive). As a result, it has a much lower mortality probability, even in the poorest environments. A similar pattern is observed in the overconservative strategy, but the faster-growing trees have lower mortality, as this strategy allocates more to survival as the environment improves (tolerant-responsive). The conservative and overconservative allocation strategies correspond to more shade-tolerant species. The prudent strategy displays a counterintuitive increase in mortality of faster-growing trees, and this arises because trees in better environments allocate less to survival, so they grow faster, but at the cost of reduced survival. The prudent strategy corresponds to species that prioritize growth and reaching reproductive size.

By varying the two parameters describing the resource allocation strategy, a wide range of shapes of the within-species mortalitygrowth relationship can be generated (Fig. 5c), analogous to those in natural forests (Supplementary Fig. 1). The tolerance parameter and 95th quantile of the growth rate for each species can be calculated from these simulated within-species mortality-growth curves, and a strong interspecific growth-mortality trade-off is produced (Fig. 5d). It is also possible to simulate a forest that is dominated by intolerant strategies, as found in the more disturbance-prone forests that we studied. On the basis of 1,000 random simulations each of forests 
with a wide range of strategies (the 25 strategies in Fig. $5 c$ ) and forests with a narrower range of 25 strategies, the correlation for the interspecific growth-mortality trade-off is stronger for the forest with a more even distribution of allocation strategies (Supplementary Fig. 7). The maximum correlation coefficient was similar for both simulated forest types, illustrating that despite generally weaker relationships, the trade-off can still arise even with a narrow range of strategies, as we found in our empirical analyses.

\section{Discussion}

Life-history trade-offs, including the interspecific growth-mortality trade-off, have been proposed as an important paradigm for explaining tree species diversity in tropical forests. Our analyses of 1,111 tree species in ten forests spanning all major tropical regions on Earth showed that the growth-mortality trade-off emerged at the global scale, consistent with the idea that unavoidable evolutionary tradeoffs shape adaptive variation in tree life-history strategies. However, the growth-mortality trade-off was not observed in every forest. The less dynamic forests exhibited stronger growth-mortality trade-offs, whereas the four more disturbance-prone forests exhibited weaker or no trade-offs. Our findings raise questions about the extent to which the growth-mortality trade-off contributes to diversity maintenance by equalizing fitness, and they suggest the hypothesis that tropical forests exhibiting a weaker trade-off would require stronger stabilizing or other forms of equalizing coexistence mechanisms to maintain species diversity. ${ }^{9-11,24}$ While differences in realized rates of population growth ultimately determine the ability of species to coexist, the growth-mortality trade-off may not be a universally applicable organizing framework for understanding diversity maintenance and community structure in tropical forests.

Our approach of using within-species mortality-growth relationships to estimate tolerance and responsiveness, which have been identified as important dimensions of resource allocation strategy, $3,18,19,25$ allowed us to explore why some forests exhibited the tradeoff whereas others did not. The reasons seem to lie in the diversity of resource allocation strategies (as estimated by the empirical tolerance 
and responsiveness parameter values) of the species in these forests, and our analyses of a theoretical demographic allocation model supported this interpretation. Among forests exhibiting the growth-mortality trade-off, there was a more even representation of toleranceresponsiveness strategies among species. In contrast, in the forests with little evidence of the growth-mortality trade-off, tolerant species were uncommon and sometimes altogether absent, resulting in a more restricted range of resource allocation strategies. When the variation in resource allocation strategies is smaller than the variation in resource access and acquisition, then expected trade-offs may not be observed, whereas the converse scenario allows trade-offs such as the growth-mortality trade-off to be more visible. ${ }^{21,26,27}$ Our empirical findings support this idea, as do our theoretical analyses: trade-offs in resource allocation are built into the strategies that we modelled (via the $\delta$ parameters) and hence into every simulated forest, but, keeping the range of environmental conditions constant across simulations, only forests with a wide range of resource allocation strategies strongly express the growth-mortality trade-off. Thus, variation in tree species' resource allocation strategies may not only be an important mechanism giving rise to the growth-mortality trade-off but also play a role in species coexistence in tropical forests.

The variation in the strength of the growth-mortality trade-off that we found across these forests may be partly due to the extent to which the species in them have been filtered for tolerance versus responsiveness strategies. While biogeographic, evolutionary and ecological forces determine regional species pools, the assembly of tree communities from these pools is shaped by the local environment, and these processes ultimately affect the resource allocation strategies that are locally adaptive. ${ }^{28,29}$ Forests in which tolerance strategies were favored were also forests in which a range of strategies was present and the trade-off was more strongly observed. In these forests, adaptations to tolerate resource limitation seem to anchor the growthmortality trade-off and represent the constraint end of a wide range of permissible strategies that are differentially favored at any time point in a shifting mosaic of patches. ${ }^{30} \mathrm{~A}$ forest type with only tolerant species, however, cannot exist, because eventually trees die, and there are patch dynamics ${ }^{30}$ that favor responsiveness. However, forests in which tolerance strategies are virtually absent can exist, because 
axes orthogonal to variation in mortality-growth relationships (such as allocation to reproduction ${ }^{31,32}$ ) may be more important in defining life histories in these forests, where disturbances are large and/or frequent, and early and ample reproduction may be particularly critical to population persistence. ${ }^{19}$ In such forests, the growth-mortality trade-off may not observed because a full spectrum of tolerance-responsiveness strategies is not present.

Compared with the species-specific responsiveness parameter, estimates of the tolerance parameter were more strongly correlated across census intervals, suggesting that tolerance of resource limitation is a more constrained life-history trait. The greater temporal variation in the responsiveness parameter suggests that it is a less constrained life-history trait in that the consequences for survival of previously growing at a given rate may be more environmentally determined. If so, then this may also explain why the growth-mortality trade-off was not observed in the more disturbance-prone forests, in which strategy variation was more defined by responsiveness. There are likely to be sources of mortality, such as drought, lightning or other disturbances that cannot be avoided, even if a tree has access to ample resources in an environment favorable for growth and/or allocates those resources to reducing the risk of death. Likewise, to the extent that allocation to reproduction diverts resources away from growth and survival functions, it may also influence the within-species mortality-growth relationship, potentially generating greater variation through time in a species' responsiveness parameter. Our study focused on juvenile to adult trees, which comprises most of their lifespan, but it would be instructive to evaluate whether the same patterns hold at the seedling stage, which comprises a high-mortality gauntlet through which trees must pass.

Simulations from our theoretical demographic allocation model showed that in a heterogeneous environment, even if tree species differ only in resource allocation strategies, the growth-mortality tradeoff can arise provided there is sufficient variation in strategies. In nature, however, our understanding of resource allocation strategies, as well as their plasticity and fitness consequences in plants, particularly in longer-lived organisms such as trees, is still rudimentary. In part, this is because resource allocation strategies are hard to quantify and so are often inferred from functional trait variation. ${ }^{33-35}$ There are several 
complications of this approach. Traits integrate multiple functions relevant to different vital rates, and due to phenotypic integration, different combinations of trait expressions can yield similar demographic outcomes. ${ }^{36}$ Trait expression also changes substantially with the environment and through ontogeny. ${ }^{37,38} \mathrm{As}$ a result, functional trait variation may not accurately capture resource allocation strategies or strongly correlate with whole-plant performance. 6,12,13,39 For these reasons, in this study, we estimated resource allocation strategies on the basis of the tolerance and responsiveness parameters of the withinspecies mortality-growth relationship. We suggest that our understanding of tree life histories is unlikely to be dramatically advanced by further observational studies describing large-scale patterns in trait variation in relation to demography. Future studies should use process models parameterized with empirical data to identify physiological and allocation-based mechanisms leading to tolerance and responsiveness and should collect longitudinal data on individual allocation to reproduction to integrate the key components of lifetime fitness to better understand tree life-history strategies.

\section{Methods}

Study sites and data. The data on tree mortality and stem diameter growth were obtained from ten plots in the Center for Tropical Forest Science ForestGEO global network of tropical forest dynamics plots, in which all trees $\geq 1 \mathrm{~cm}$ in stem DBH (that is, $1.3 \mathrm{~m}$ above the ground) are censused for survival and remeasured for diameter every $\sim 5 \mathrm{yr}$ (Supplementary Table 1). ${ }^{40}$ Plots with at least three censuses were used so that the mortality probability given prior growth could be estimated for each individual tree, with prior growth being estimated during the interval spanning the first two censuses and mortality being estimated from the second to third census, for any three consecutive censuses. Several plots had multiple three-census sets, so we analyzed the relationship between mortality and prior growth for a total of 21 forest plot $\times$ census interval combinations, comprising a total of 1,111 woody species (that is, excluding palms) and a stem diameter range of 1 to $201 \mathrm{~cm}$ across all species in our dataset. To compare plots with only three censuses to those with more than three censuses, only the 
first three censuses in a plot were considered for some analyses and figures, comprising 1,097 woody species across all plots. All analyses were performed in $\mathrm{R}$ statistical software version 3.6.1. ${ }^{41}$

Interspecific growth-mortality trade-off and within-species mortality-growth relationship. The interspecific growth-mortality tradeoff is thought to be a trade-off between the ability to survive when resource availability is low and the ability to grow quickly when resources are plentiful.6,10,16 We therefore estimated the trade-off as the correlation between species' predicted mortality rate of a 1-cm-diameter tree that did not grow in diameter in the previous census interval (that is, the tolerance parameter in Fig. 1b) and the 95th quantile of the distribution of diameter growth rates. Because species' mortality and growth rates were not normally distributed, we conducted Pearson correlation tests on log-transformed rates and used the best-fit lines from standardized major axis regression, ${ }^{42}$ as implemented in the smatr package ${ }^{43}$ to visualize the growth-mortality trade-off.

We estimated the tolerance parameter from a model of the withinspecies mortality-growth relationship that was fit separately for each species with (1) at least 200 individual trees having data on mortality given prior growth and (2) at least 5 trees dying from the second to third census, across three consecutive censuses. Because mortality can be a rare event, an abundance threshold of 200 individuals was used to ensure that the mortality-growth relationship was well estimated. Our goal was to estimate species-specific mortality-growth relationships, rather than forest-wide demography. Therefore, we did not use a hierarchical modelling approach, which would have allowed us to include all species, because parameter estimates for rarer species would shrink towards estimates for species with abundant data. ${ }^{44}$ Models were run for each species in each plot $x$ census interval combination separately, because none of our statistical inferences relies on the assumption of independence of a species' responses across different censuses and because we were interested in estimating temporal variation in model parameters that could be linked to temporally varying factors such as climate.

We estimated the within-species mortality-growth relationship using a generalized linear model, as implemented in the glm function in R. For any three censuses, the mortality probability $\left(p_{i j}\right)$ of tree $i$ of 
species $j$ during the second to third census interval was assumed to be Bernoulli distributed, $p_{i j} \sim \operatorname{Bernoulli}\left(y_{i j}\right)$, where $y$ is 1 if the tree dies and 0 if it remains alive. Using a logit link function, we modelled mortality probability as a function of the log-transformed diameter $\left(D_{i j}\right)$ at the start of the second census and the power-transformed prior growth $\left(\tau_{i j}\right)$ of the tree's main stem. Transformations were used due to the skewness of the distributions of diameter and prior growth. The power transformation of growth rate has the advantage of retaining in the analysis stems with small negative growth rates resulting from slight contractions in diameter related to tree water status or slight errors in diameter measurement, which are frequent among slow-growing trees. Thus, $\tau_{i j}=g_{i j}{ }^{0.45}$ for $g \geq 0$ and $\tau_{i j}=-\left(-g_{i j}\right)^{0.45}$ for $g<0$. A power of 0.45 has been found to be most effective at reducing skewness in these tree plot data. ${ }^{45}$ The prior growth of each tree $i$ of species $j$ was calculated as the annual diameter increment $\left(g_{i j}\right)$, which is the difference in diameters of the tree's main stem at two consecutive censuses divided by the time interval between the censuses. Stems with large positive or negative growth values were excluded because they were likely to be erroneous and bias analyses, using a model based on the standard deviation of remeasured diameters from the 1995 and 2000 censuses at the $\mathrm{BCl}$ plot. ${ }^{46}$ In addition, any tree in which the second diameter measurement was $>4$ standard deviations below the first was excluded. Any growth rate $>75 \mathrm{~mm} \mathrm{yr}^{-1}$ was also excluded. Thus, the following generalized linear model with a binomial error distribution was fit for each species using the data meeting the above criteria, for any three consecutive censuses: $\operatorname{logit}\left(p_{i j}\right) \sim \beta_{0}+\beta_{1} \ln \left(D_{i j}\right)+\beta_{2} \tau_{i j^{\prime}}$

We obtained estimates of the intercept $\left(\beta_{0}\right)$ and slope $\left(\beta_{2}\right)$ of the within-species mortality-growth relationship for each species in each plot $\times$ census interval combination. Tolerance $\left(\beta_{0}\right)$ and responsiveness $\left(\beta_{2}\right)$ parameters vary from $-\infty$ to $+\infty$ on the logit scale. When backtransformed to the probability scale, the tolerance parameter represents the mortality rate of a tree $1 \mathrm{~cm}$ in diameter previously growing at a rate of $0 \mathrm{~cm} \mathrm{yr}^{-1}$, and the responsiveness parameter represents the change in mortality probability with variation in growth rate in the prior census interval. Our biological interpretation of these parameters was described in the Introduction (Fig. 1b).

We performed model diagnostics using the DHARMa ${ }^{47}$ and broom ${ }^{48}$ packages, including comparing observed versus expected residuals 
(Q-Q plots), standardized residuals versus predicted values and versus independent variables $\left(\left(\ln \left(D_{i j}\right)\right.\right.$ and $\left.\tau_{i j}\right)$, and tests for outliers and overdispersion. Overall, the diagnostic tests showed good fits of our model to the data. We evaluated the goodness of fit of our withinspecies mortality-growth models relative to a simpler model of mortality as a function of only diameter using model selection based on Akaike's information criterion (AIC) and PseudoR ${ }^{2}$ (refs. 49,50) for each plot and census year combination. Differences in AIC and Pseudo ${ }^{2}$ showed that improvements in explanatory power were achieved when prior growth rate was added to the model as a predictor of mortality (Supplementary Table 2).

Growth rate $\left(\mathrm{cm} \mathrm{yr}^{-1}\right)$ was calculated as described above for each tree using the first and second censuses of any three-census interval, and the 95th quantile of the growth rate distribution was determined. We chose not to use relative growth rate because, although it attempts to account for the effects of size on growth, relative growth rate is itself size-dependent and declines as individuals grow, ${ }^{51}$ which can be problematic for large trees.

We evaluated whether using size-standardized growth and mortality rates for each species would result in better estimation of the growth-mortality trade-off than our approach for quantifying the growth-mortality trade-off. To do this, we fit separate linear and nonlinear models of growth (five models) and mortality (four models) as functions of diameter, chose the most supported model for each species on the basis of AIC, and predicted growth and mortality at the 25th and 50th species-specific quantiles of diameter. Our analyses indicated that contrary to improving inferences, the predicted growth and mortality at a given diameter produced poor predictions for many species for two reasons. First, the confidence intervals on prediction were quite large, since growth and mortality often do not vary strongly with diameter, as has been previously shown. ${ }^{52}$ Second, given the structural complexity of old-growth tropical forests and the stochasticity of death, there is no common diameter that did not produce biased mortality predictions for some species, making the predictions incomparable across species. When all tree deaths happened to fall above or below the diameter quantile, the mortality prediction at that diameter was near zero, creating a large outlier in the mortality rate. Thus, using predicted growth and mortality at 
a given diameter creates the appearance of size standardization, but it introduces undesirable inaccuracies and uncertainties that can be avoided with our approach.

We chose not to conduct a phylogenetic comparative analysis because if there is no phylogenetic effect (that is, if more closely related species are not more similar in trait variation), then incorporating phylogenetic information into analyses may be inappropriate. ${ }^{53-55}$ This is especially of concern since our analyses include tree species from across the world's major tropical regions, which are still poorly known from phylogenetic and sometimes even taxonomic perspectives. As a result, phylogenetic topologies could be incorrect and will also have many polytomies, possibly producing artefacts in phylogenetic comparative analyses. We therefore chose to avoid these uncertainties and potential biases.

Variation in resource allocation strategies. We used the medians of tolerance and responsiveness across all datasets (that is, all species, plots and three census interval combinations) to define four resource allocation strategy groups defined by the within-species mortalitygrowth relationship. Species with a tolerance (that is, the intercept of the mortality-growth relationship) less than the median were classified as tolerant, whereas those with a tolerance greater than the median were classified as intolerant. Since the slopes of the mortality-growth relationship were nearly always negative, species with a responsiveness less than the median (that is, a steeper negative slope) were classified as responsive, whereas those with a responsiveness greater than the median were classified as unresponsive (that is, a slope closer to zero or positive). We performed this classification separately for each forest $\times$ census interval combination. It is important to note that these tolerance-responsiveness strategy groups depend on the particular forests included and do not represent an absolute tolerance-responsiveness spectrum. They are, however, a useful way to compare the frequencies of different tolerance-responsiveness strategies across the forests in our data. The variation in tolerance and responsiveness parameters across forests, using estimates from models fit for the first three-census interval for each plot, was also visualized using principal components analysis as implemented in the prcomp function in $\mathrm{R}$ on the parameter values scaled by subtracting the mean and dividing by the standard deviation across species. 
Theoretical demographic allocation model. We developed a theoretical demographic allocation model to describe a community of tree species representing a continuum of resource allocation strategies that differ in allocation to functions promoting growth and survival. Our hypothesis is that species differ in two dimensions of resource allocation strategy: (1) the minimum amount, regardless of its growing environment, that a tree allocates to survival functions, analogous to the tolerance parameter in our empirical analyses, and (2) how much more or less a tree in an environment with greater resource availability allocates to survival functions, compared with a tree with lower access to resources, analogous to the responsiveness parameter in our empirical analyses. We define parameters describing these dimensions and simulate the growth and survival with respect to a heterogeneous environment of individuals of tree species that vary only in these two dimensions of their allocation strategies. The model is described in detail and analyzed in Supplementary Appendix 2.

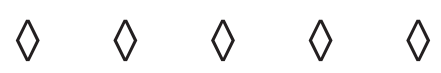

Reporting Summary Further information on research design is available in the Nature Research Reporting Summary at https://www.nature.com/articles/ s41559-020-01340-9\#Sec13

Data availability The data supporting the findings of this study are deposited at https://forestgeo.github.io/fgeo/.

Code availability The programming code supporting the findings of this study is deposited at https://forestgeo.github.io/fgeo/.

Acknowledgments This research was conducted during Analytical Workshops held by the Smithsonian Center for Tropical Forest Science Forest GEO program, supported by the National Science Foundation of the United States, grant no. DEB1046113. S.E.R. was supported by a Faculty Development Leave Fellowship from the University of Nebraska-Lincoln and a Short-Term Fellowship from the Japan Society of the Promotion of Science. We thank A. Zera for insightful discussions of tradeoffs and constructive comments on an earlier version of this manuscript. This work was generated using data from the Center for Tropical Forest Science/Smithsonian Institution Forest Global Earth Observatory network (http://www.forestgeo.si.edu/). Individual plot data collection and management and authors were supported by grants from the National Science Foundation of the United States (grant nos EF1137366, BSR-9015961, DEB-1516066, BSR-8811902, DEB- 9411973, DEB-008538, 
DEB-0218039 and DEB-0620910), the Council of Agriculture of Taiwan (grant nos 93AS-2.4.2-FI-G1(2) and 94AS-11.1.2-FI-G1(1)), the Ministry of Science and Technology of Taiwan (grant nos NSC92-3114-B002-009, NSC98-2313-B-029-001-MY3 and NSC98-2321-B-029-002), the Forestry Bureau of Taiwan (grant nos 92-00-2-06 and TFBM-960226), the Taiwan Forestry Research Institute (grant no. 97 AS- 7.1.1.F1G1), the Mellon Foundation, the International Institute of Tropical Forestry of the USDA Forest Service, the University of Puerto Rico, the 1923 Fund, the Centre for Ecology and Hydrology, the German Academic Exchange Services (DAAD), Sarawak Forest Department, Sarawak Forestry Corporation, Global Environment Research Fund of the Ministry of the Environment Japan (grant no. D-0901), Japan Society for the Promotion of Science (grant no. 17H04602), The Wildlife Conservation Society, the Institut Congolais pour la Conservation de la Nature, the Thai National Parks Wildlife and Plant Conservation Department, the Center for Tropical Forest Science Arnold Arboretum Asia Program, the Smithsonian Tropical Research Institute, and the Luquillo Long Term Ecological Research programme (LuqLTER). We also thank the hundreds of people who contributed to the collection and management of the data from the plots.

Author contributions S.E.R. conceived and designed the study, assembled and analyzed the data, and wrote the manuscript. S.E.R., G.L. and M.D. designed and analyzed the theoretical model. R.S.C., S.J.D., M.D., S.M.M. and S.J.W. made important contributions to interpreting the results and to writing and revising the manuscript. R.S.C., S.J.D., P.S.A., S.B., C.-H.C.-Y., S.E., C.E.N.E., C.F., R.B.F., C.V.S.G., I.A.U.N.G., T.H., C.F.H., S.P.H., A.I., A.R.K., Y.T.L., Y.C.L., J.-R.M., M.B.M., P.O., A.S., I.-F.S., S.T., J.T., T.Y., S.L.Y. and J.K.Z. contributed to the acquisition of the data used in the paper and in writing the manuscript. All authors have given final approval to publish this manuscript and agree to be accountable for the aspects of the work that they conducted.

Competing interests The authors have declared there are no competing interests.

Additional information Supplementary information follows the References.

\section{References}

1. Loehle, C. Tree life history strategies: the role of defenses. Can. J. For. Res. 18, 209-222 (1988).

2. Kitajima, K. Relative importance of photosynthetic traits and allocation patterns as correlates of seedling shade tolerance of 13 tropical trees. Oecologia $\mathbf{9 8}$, 419-428 (1994).

3. Kobe, R. K., Pacala, S. W., Silander, J. A. \& Canham, C. D. Juvenile tree survivorship as a component of shade tolerance. Ecol. Appl. 5, 517-532 (1995).

4. Rees, M., Condit, R., Crawley, M., Pacala, S. \& Tilman, D. Long-term studies of vegetation dynamics. Science 293, 650-655 (2001). 
5. Russo, S. E., Brown, P., Tan, S. \& Davies, S. J. Interspecific demographic tradeoffs and soil-related habitat associations of tree species along resource gradients. J. Ecol. 96, 192-203 (2008).

6. Wright, S. J. et al. Functional traits and the growth-mortality trade-off in tropical trees. Ecology 91, 3664-3674 (2010).

7. Hubbell, S. P. \& Foster, R. B. Short-term dynamics of a neotropical forest: why ecological research matters to tropical conservation and management. Oikos 63, 48-61 (1992).

8. Stephenson, N. L. et al. Causes and implications of the correlation between forest productivity and tree mortality rates. Ecol. Monogr. 81, 527-555 (2011).

9. Adler, P. B., HilleRisLambers, J. \& Levine, J. M. A niche for neutrality. Ecol. Lett. 10, 95-104 (2007).

10. Hubbell, S. P. The Unified Neutral Theory of Biodiversity and Biogeography (Princeton Univ. Press, 2001).

11. Chesson, P. Mechanisms of maintenance of species diversity. Annu. Rev. Ecol. Syst. 31, 343-366 (2000).

12. Poorter, L. et al. Are functional traits good predictors of demographic rates? Evidence from five neotropical forests. Ecology 89, 1908-1920 (2008).

13. Paine, C. E. T. et al. Globally, functional traits are weak predictors of juvenile tree growth, and we do not know why. J. Ecol. 103, 978-989 (2015).

14. Cailleret, M. et al. A synthesis of radial growth patterns preceding tree mortality. Glob. Change Biol. 23, 1675-1690 (2017).

15. Wyckoff, P. H. \& Clark, J. S. The relationship between growth and mortality for seven co-occurring tree species in the southern Appalachian Mountains. J. Ecol. 90, 604-615 (2002).

16. Kobe, R. K. Intraspecific variation in sapling mortality and growth predicts geographic variation in forest composition. Ecol. Monogr. 66, 181-201 (1996).

17. Kobe, R. K. Light gradient partitioning among tropical tree species through differential seedling mortality and growth. Ecology 80, 187-207 (1999).

18. Chapin, F. S., Autumn, K. \& Pugnaire, F. Evolution of suites of traits in response to environmental stress. Am. Nat. 142, S78-S92 (1993).

19. Grime, J. P. Evidence for the existence of three primary strategies in plants and its relevance to ecological and evolutionary biology. Am. Nat. 111, 1169-1194 (1977).

20. Westoby, M., Warton, D. \& Reich, P. B. The time value of leaf area. Am. Nat. 155, 649-656 (2000).

21. Zera, A. J. \& Harshman, L. G. The physiology of life history trade-offs in animals. Annu. Rev. Ecol. Syst. 32, 95-126 (2003).

22. Russo, S. E., Davies, S. J., King, D. A. \& Tan, S. Soil-related performance variation and distributions of tree species in a Bornean rain forest. J. Ecol. 93, 879-889 (2005).

23. Obeso, J. R. The costs of reproduction in plants. N. Phytol. 155, 321-348 (2002). 
24. Roxburgh, S. H., Shea, K. \& Wilson, J. B. The intermediate disturbance hypothesis: patch dynamics and mechanisms of species coexistence. Ecology 85, 359-371 (2004).

25. Lambers, H. \& Poorter, H. Inherent variation in growth rate between higher plants: a search for physiological causes and ecological consequences. $A d v$. Ecol. Res. 34, 187-261 (1992).

26. Metcalf, C. J. E. Invisible trade-offs: Van Noordwijk and de Jong and life-history evolution. Am. Nat. 187, iii-v (2016).

27. Van Noordwijk, A. J. \& Jong, G. D. Acquisition and allocation of resources: their influence on variation in life history tactics. Am. Nat. 128, 137-142 (1986).

28. Condit, R. et al. Importance of demographic niches to tree diversity. Science 313, 98-101 (2006).

29. Ricklefs, R. E. Community diversity: relative roles of local and regional processes. Science 235, 167-171 (1987).

30. Bormann, F. H. \& Likens, G. E. Pattern and Process in a Forested Ecosystem (Springer, 1979).

31. Salguero-Gómez, R. et al. Fast-slow continuum and reproductive strategies structure plant life-history variation worldwide. Proc. Natl Acad. Sci. USA 113, 230-235 (2016).

32. Rüger, N. et al. Beyond the fast-slow continuum: demographic dimensions structuring a tropical tree community. Ecol. Lett. 21, 1075-1084 (2018).

33. McGill, B. J., Enquist, B. J., Weiher, E. \& Westoby, M. Rebuilding community ecology from functional traits. Trends Ecol. Evol. 21, 178-185 (2006).

34. McMahon, S. M., Metcalf, C. J. E. \& Woodall, C. W. High-dimensional coexistence of temperate tree species: functional traits, demographic rates, life-history stages, and their physical context. PLoS ONE 6, e16253 (2011).

35. Reich, P. B. The world-wide 'fast-slow' plant economics spectrum: a traits manifesto. J. Ecol. 102, 275-301 (2014).

36. Marks, C. O. \& Lechowicz, M. J. Alternative designs and the evolution of functional diversity. Am. Nat. 167, 55-66 (2006).

37. Visser, M. D. et al. Functional traits as predictors of vital rates across the life cycle of tropical trees. Funct. Ecol. 30, 168-180 (2016).

38. Detto, $M . \& X u, X$. Optimal leaf life strategies determine $V_{c, \max }$ dynamic during ontogeny. New Phytol. https://doi.org/10.1111/nph.16712 (2020).

39. Poorter, L. \& Bongers, F. Leaf traits are good predictors of plant performance across 53 rain forest species. Ecology 87, 1733-1743 (2006).

40. Anderson-Teixeira, K. J. et al. CTFS-ForestGEO: a worldwide network monitoring forests in an era of global change. Glob. Change Biol. 21, 528-549 (2015).

41. R Core Team R: A Language and Environment for Statistical Computing version 3.6.1 (R Foundation for Statistical Computing, 2017).

42. Warton, D. I., Wright, I. J., Falster, D. S. \& Westoby, M. Bivariate line-fitting methods for allometry. Biol. Rev. 81, 259-291 (2006). 
43. Warton, D. I., Duursma, R. A., Falster, D. S. \& Taskinen, S. smatr 3- an R package for estimation and inference about allometric lines. Methods Ecol. Evol. 3, 257-259 (2012).

44. Gelman, A., Carlin, J. B., Stern, H. S. \& Rubin, D. B. Bayesian Data Analysis 2nd edn (Chapman and Hall/CRC, 2004).

45. Kenfack, D., Chuyong, G., Condit, R., Russo, S. \& Thomas, D. Demographic variation and habitat specialization of tree species in a diverse tropical forest of Cameroon. For. Ecosyst. 1, 22 (2014).

46. Condit, R. et al. Tropical forest dynamics across a rainfall gradient and the impact of an El Niño dry season. J. Trop. Ecol. 20, 51-72 (2004).

47. Hartig, F. DHARMa: Residual Diagnostics for Hierarchical (Multi-Level / Mixed) Regression Models. R package version 0.3.3.0 (2020).

48. Robinson, D. broom: An R Package for Converting Statistical Analysis Objects Into Tidy Data Frames. R package version 2 (2014); https://arxiv.org/ abs/1412.3565

49. Nagelkerke, N. J. D. A note on a general definition of the coefficient of determination. Biometrika 78, 691-692 (1991).

50. Long, J. S. Regression Models for Categorical and Limited Dependent Variables (Sage, 1997).

51. Paul-Victor, C., Züst, T., Rees, M., Kliebenstein, D. J. \& Turnbull, L. A. A new method for measuring relative growth rate can uncover the costs of defensive compounds in Arabidopsis thaliana. New Phytol. 187, 1102-1111 (2010).

52. Coomes, D. A. \& Allen, R. B. Effects of size, competition and altitude on tree growth. Ecol. Lett. 95, 1084-1097 (2007).

53. Björklund, M. Are 'comparative methods' always necessary? Oikos $\mathbf{8 0}, 607-612$ (1997).

54. Losos, J. B. Uncertainty in the reconstruction of ancestral character states and limitations on the use of phylogenetic comparative methods. Anim. Behav. 58, 1319-1324 (1999).

55. Losos, J. B. Seeing the forest for the trees: the limitations of phylogenies in comparative biology. Am. Nat. 177, 709-727 (2011).

56. Stearns, S. C. The Evolution of Life Histories (Oxford Univ. Press, 1992).

57. Rose, K. E., Atkinson, R. L., Turnbull, L. A. \& Rees, M. The costs and benefits of fast living. Ecol. Lett. 12, 1379-1384 (2009).

58. Makana, J.-R. et al. Demography and biomass change in monodominant and mixed old-growth forest of the Congo. J. Trop. Ecol. 27, 447-461 (2011). 